\title{
Relational, Flexible, Everyday: Learning from Ethics in Dementia Research
}

\author{
James Hodge ${ }^{1}$, Sarah Foley ${ }^{2}$, Rens Brankaert ${ }^{3}$, Gail Kenning $^{4}$, Amanda Lazar $^{5}$, \\ Jennifer Boger ${ }^{6}$, Kellie Morrissey ${ }^{7}$ \\ ${ }^{1}$ Open Lab, Newcastle University, Newcastle upon Tyne, UK, j.hodge1@ncl.ac.uk \\ ${ }^{2}$ School of Applied Psychology, University College Cork, Ireland, sarah.foley@ucc.ie \\ ${ }^{3}$ Industrial Design, University of Technology \& Institute of Allied Health Professions, Fontys University \\ of Applied Sciences, Eindhoven, Netherlands, r.g.a.brankaert@tue.nl \\ ${ }^{4}$ University of Technology Sydney, Australia, gail.kenning@uts.edu.au \\ ${ }^{5}$ College of Information Studies, University of Maryland, College Park, Maryland, United States, \\ lazar@umd.edu \\ ${ }^{6}$ University of Waterloo, Waterloo, Ontario, Canada, jboger@uwaterloo.ca \\ ${ }^{7}$ School of Design, University of Limerick, Limerick, Ireland, Kellie.Morrissey@ul.ie
}

\begin{abstract}
Engaging in participatory research in HCI raises numerous ethical complexities such as consent, researcher relationships, and participant compensation. Doing $\mathrm{HCI}$ work in the area of dementia amplifies these issues, and researchers in this area are modelling ethical stances to ensure researcher-participant relationships focus on meaningful engagement and care. This paper presents an insight into the kinds of ethical foci required when doing design research with people living with dementia and their carers. We interviewed $22 \mathrm{HCI}$ researchers with experience working in dementia care contexts. Our qualitative analysis outlines subsequent lessons-learned, such as recognition of the participants, self -care, research impact, and subjectivity in ethical review boards. Furthermore, we found the complexity of navigating both "everyday" and more formal, institutional ethics in dementia research has implications beyond the context of working with people with dementia and outline key considerations for ethical practices in socially orientated HCI research.
\end{abstract}

\section{Author Keywords}

Dementia; ethics; emotion; care; lived experience; relational

\section{CSS Concepts}

- Human-centered computing User studies •

Human-centered computing Empirical studies in $\mathrm{HCI}$

\section{INTRODUCTION}

At a time when the ethics surrounding technology design

Permission to make digital or hard copies of part or all of this work for personal or classroom use is granted without fee provided that copies are not made or distributed for profit or commercial advantage and that copies bear this notice and the full

citation on the first page. Copyrights for third-party components of this work must be

honored. For all other uses, contact the Owner/Author.

CHI '20, April 25-30, 2020, Honolulu, HI, USA

(C) 2020 Copyright is held by the owner/author(s).

ACM ISBN 978-1-4503-6708-0/20/04.

DOI: https://doi.org/10.1145/3313831.3376627 and deployment are receiving increased attention [78], from data governance [2] to privacy [100] to poorly considered technological design [29], it is crucial for established professionals to reflect on both tacit and codified ethics [43]. In response to this need, HCI researchers are reflecting on the ethical challenges they face throughout their research process [68], with conversations largely occurring in venues such as Town Halls [11,19,38,67] and conference workshops at ACM venues $[22,87,97,98]$. A particular interest has arisen in working with participants in sensitive contexts, due to the unique challenges that arise due to what it means to participate when capacity is difficult to ascertain $[35,52,55]$, in verbal processes for people who are often not verbal [49,51,53], and recognition of participants involvement throughout the study $[33,56,92,94]$. To date, these conversations have been useful for sharing experiences that are often based on a single research project. Yet we are missing an understanding of how researchers in a diverse array of contexts handle ethical decisions. As an example of a topic that emerged in our paper through considering different viewpoints, Ethical Review Boards (ERBs) are in place to ensure research is following standard ethical principles, with the aim of protecting the participants, researchers and research institutions [75]. Despite playing a key role and coming up repeatedly in town halls in terms of questioning how the HCI community can think about ethics given the variation (or lack) of ERBs in the international context, there has been little research to date that examine the impact of ERBs on research in HCI.

In this study, we take design ethics in dementia and HCI research as a case study to reflect as a community of practice [3] and to elucidate wider concerns about ethics in HCI research. Dementia is a neurodegenerative condition that affects people differently, but often involves changes to short-term memory, orientation, and decision making and 
results in an increased need for care [101]. Dementia is a useful case to study in terms of ethics given shifts in ways of viewing the condition. The view of dementia as state of deficiency has been criticized as a "medicalisation of deviance" [13], where the person with dementia is positioned as a passive "patient" whose dementia must be treated rather than understood, and little consideration is given to the agency or the need for a continued sense of purpose and belonging. In response to the medicalisation of the experience of dementia, person-centered approaches have highlighted the need for socially-oriented care, in which the individual is positioned central to the advancement of their care $[32,59]$. This approach informs recent work in HCI and dementia, which focuses on 'in the moment' meaning-making as the basis of design $[35,46,48,83]$. Influenced by these shifts in care thinking, HCI researchers have sought to design technologies that evoke emotion, creativity and inclusion by working with and advocating for people living with dementia, mirroring a similar shift in design in social care more generally [82] .

However, even as these views of dementia evolve in research and practice, research shows that work in sensitive settings such as dementia can raise concern from Ethical Review Boards (ERBs). Pachana et al. further highlights that committees may be "subject to the same biases and stereotypes present in the general population" [74]. ERBs that are unaware of such biases, may focus on the aims of protection, as opposed to the approval of research that attends to topics such as agency and ensure meaningful participation. A further complexity arises given that ERB decisions vary even within the same country or region [28]. This is because the decisions and reasonings are not only made at a university level, but influenced by cultural and local norms and customs [28]. Thus, the disciplinary changes in working with populations such as dementia are not necessarily matched at the level of those who make decisions about what research is and is not allowed when carrying out participatory work with participants who are considered 'vulnerable', this tension is a key focus that we attend to in this study.

To gain an understanding of ethical experiences and practices in the field of HCI and dementia, we interviewed 22 researchers from diverse countries, institutions, and disciplines. Our analysis uncovers tensions arising from institutional ethical practices in socially oriented research. While ERBs vary significantly in their cultural and disciplinary approaches to dementia research, our findings reveal the tensions that arise in participatory research due to ERBs' tending to focus on protection of participants, which raises concerns with acknowledging participants and building relationships. Through our interviews, researchers reflected on how ERBs could be more reflexive bodies, where researchers can seek support, guidance, and collaboration from experts. Researchers also shared insights from their own cultivated practices from establishing clear expectations for participants, knowing when and how to involve participants in the research, and appropriately acknowledging the contribution that participants make to our work. From these rich findings, our study progresses from a growing body of work in HCI and dementia towards establishing a new set of fluid ethical practices to direct work in this growing area of socially-oriented HCI research.

\section{RELATED WORK}

The following sections summarise working practices around ethics in HCI and the nature of the complexities that can arise from working with technology and design in dementia research and, more broadly, in sensitive contexts.

\section{Design \& Ethics in $\mathrm{HCl}$}

$\mathrm{HCI}$ and design researchers have long recognised the role of the researcher as essential in building and maintaining relationships, and as a means of conducting engaged and impactful research [88]. Many approaches in HCI, such as participatory design [66], experience-centered design [61], feminist $\mathrm{HCI}$ [5] and value-sensitive design [39] require the researcher to work closely with participants in order to engage in open and exploratory examinations of their lived experience. The design methods employed in HCI research which seek to examine and respond to the lived experience of our participants, such as design ethnography [26], co-design [48], and the use of design probes [91] present considerable challenges for researchers navigating through emotionally and contextually complicated research settings, particularly when working with populations considered to be vulnerable. In navigating through these research decisions, the researcher is often guided, or conflicted, by institutional ethical procedures that set a precedent for ethical practices in research.

The ethical principles applied by ERBs often reflect the philosophical basis of morality and established codes of conduct shaped by culture and society [41]. In order to guide research practices, these moral and ethical judgements [28] have been applied in guidelines for research, such as WHO Operational Guidelines for Ethics Committees that Review Biomedical Research [27] and the Declaration of Helsinki [102]. While these ethical guidelines set a course for research that seeks to ensure both the participant and research institute are informed and protected, many prominent interdisciplinary research approaches, such as participatory design and qualitative work with vulnerable populations in HCI, can be considered ethically questionable by ERBs. Bell [8] argues that many ERBs' approaches to ethics align more with biomedical and experimental scientific methods, which fail to reflect the multiple ways of generating knowledge that encompass the third wave of HCI $[12,56]$. Willig suggests that for qualitative researchers, 'ethical issues arise from the very 
beginning of the research, they stay with us throughout our interactions with our research participants, and they continue to be relevant throughout the process of dissemination of the research findings' [21], and call for an adaptable approach to ethical research design.

The introduction of technology and design has further ethical implications within sensitive design contexts. For example, technology may bring expectations of significant and lasting improvement to quality of life [88]; prototypes and early design probes are liable to break [35], and technologies have implications for data storage and privacy [11]. In addition to technology and design, participatory methods which have long been a central part of HCI work [20] are facing significant questioning by ERBs and other governing bodies, where discomfort with qualitative or social constructionist [40] methods can clash with 'harder' questions of computer science and engineering [80].

Recent work in HCI has begun to examine the central role of ethics in relation to healthcare $[6,88]$ and culturally contextual research [9]. This work suggests that there is a need for contextual and continued ethics in HCI, which is sensitive to both the relational and technological challenges facing researchers. In order to build an empirical basis for conducting ethical research in socially-orientated HCI research, this paper presents findings from researchers who work in contexts which present a number of institutional and relational ethical challenges - dementia care [3]. In order to contextualise this research, in the next section we briefly introduce the current state of the art in person-centered design research in $\mathrm{HCI}$ and dementia, to present the lessons learned from this community of practice as a basis for relational, flexible and everyday ethics in socially-orientated HCI research.

\section{Ethics in Context: Dementia Care and $\mathrm{HCl}$}

Dementia is a neurodegenerative condition that produces varying cognitive changes [101]. Given that people may experience changes to their ability to problem solve, make judgements, and can require an increasing need for care, many of the cognitive and social consequences of living with dementia can be framed as an ethical concern for the person at the heart of the condition and their family, making it a complex space for both research and care practices. Person-centered approaches to dementia care have called attention to how we communicate with people with dementia [73], debated the need for ongoing consent processes [24], questioned the contested use of lies and deception in care [30] and promoted the need to attune to embodied, non-verbal communication $[54,84]$ as key considerations in ensuring the person with dementia is respected and engaged within their own care. These practices, largely initiated within nursing and social care, have implications for research and design which seeks to work with and for people living with dementia, avoiding practices which inadvertently or disregard the experience of the person living with dementia. Design and technology solutions which focus on cognitive decline, monitoring and management, may perpetuate stereotypes and contribute further to the stigmatisation of dementia [64] . Similarly, HCI research that extends from person-centred approaches to dementia is a growing body of work which relies on relational processes as the basis of design. This has resulted in the introduction of technologies that seek to evoke positive emotions $[48,90,92,94]$, engage with participants' creativity [14,55-58,63-65] and support inclusion $[35,45,46,85,86,99]$. Participatory and co-design projects have innovated many of the methodological approaches to design necessary in order to support people living with dementia to engage meaningfully in co-design processes $[44,62]$. This includes planning for slower, longer-term projects [34], working within ecologies of care $[14,15,46,95,96]$, and navigating gate-keeping within institutions [48] .

The ethical consideration needed to ensure inclusion of the voices of people living with dementia in HCI research has resulted in a strong relational basis for design practice $[46,93,94]$. The established state-of the art based within this work has moved away from the biomedical deficit model of dementia, resulting in a number of underlying person-based values in design practice, many of which stem from the work of Tom Kitwood [50] and Dawn Brooker [17,18]. These practices include treating the person living with dementia as an individual in context; including the person living with dementia in research processes that aim to improve their quality of life; and acknowledging that dementia is a complex experience that often also includes social complexity, ageing and multi-morbidities, which require attuning to in design and research responses. These practices and design decisions offer particular ethical stances that appear essential to both the success of HCI projects in this context, and ensure the researcher-participant relationship is navigated with mutual respect and care [34]. Making these ethical decision-making processes more visible within our empirical work has the potential to critically inform the current institutional and relational ethical framing in which we currently work [73], and make more apparent considerations needed to ensure meaningful and engaged research with 'vulnerable' user groups is central to the design of technologies and systems.

This paper presents empirical evidence derived from asking researchers in the field of HCI and dementia to reflect on their ethical practices in their own research, with a view to presenting a series of considerations for how to navigate ethical decision-making in socially-orientated HCI research. We later extend the insights and reflections of our expert-researchers and contribute empirical evidence to the on-going HCI communities discussing ethical challenges 
when working within sensitive settings $[22,97,98]$. While our findings reflect the careful ethical considerations required when working with people with dementia and their care ecologies, they are based in relational and everyday ethics which have implications for the wider $\mathrm{HCI}$ community.

\section{METHODOLOGY}

Interested in the tacit and unstated practices that researchers employed in working with people living with dementia and their carers, we undertook a reflective qualitative approach to carrying out this empirical research. As researchers ourselves, we also interviewed each other to pilot our interview schedule and sense-check similarities and differences across our experience. Mindful that we were about to engage with a large number of researchers across several disciplines, and on sensitive topics, we adopted the reflexive position of 'connected knowing', as articulated by [7] which recognises disagreement or disparity between viewpoints, but adopts a strategy of empathy instead of judgement or argument. Knowledge, in connected knowing, comes from the 'inside' - of a phenomenon, an account, or an experience. Once inside, we sought to form intimate attachments to our participants' experiences which were necessarily imaginative and compassionate - constantly imagining ourselves in the place of our participants in an attempt to understand their words, actions, and meanings as they spoke about the development of their own 'everyday ethics' in dementia.

\section{Participants and recruitment}

Participants were 22 (12 women, 10 men) self-identified designers and/or researchers who reported significant experience in working with people living with dementia in the design of technologies and services. Participant demographics are summarized in table 1. Participants were recruited through purposive sampling methods [31], a method which has been judged as appropriate for building suitable samples for qualitative datasets [81], and it is advised in cases where we seek to access a particular subset of people, as all participants of a study are selected because they fit a similar profile. To begin with, we selected participants from presenters, exhibitors and authors from the 2016-2019 Dementia Lab conferences - this is an international conference featuring design and HCI work with people with dementia [103]. We also employed snowball sampling, asking participants to recommend others in their professional circles with similar experiences with design, HCI and dementia [72]. In our table, we define career stages as: early - junior researcher/lecturer, mid senior researcher/lecturer and senior - professor.

\section{Ethics}

Ethical approval was granted by Newcastle University. Each participant was emailed an overview of what would be expected from the interview and the study, and provided with information and consent form sheets. Participants have been anonymised for the purpose of privacy.

\begin{tabular}{|c|c|c|c|c|}
\hline Name & Discipline & Career Stage & Gender & Place of Practice \\
\hline Emily & Design & Mid & $\mathrm{F}$ & UK \\
\hline Verna & $\mathrm{HCI}$ & Early & $\mathrm{F}$ & Singapore \\
\hline Neville & Design & Early & M & The Netherlands \\
\hline Louise & Psychology & Early & $\mathrm{F}$ & Ireland \\
\hline Sofià & Design & Early & $\mathrm{F}$ & The Netherlands \\
\hline Isla & Psychology & Early & $\mathrm{F}$ & Ireland \\
\hline Martin & Computer Science & Student & M & United Kingdom \\
\hline Niamh & Speech \& Language & Early & $\mathrm{F}$ & United Kingdom \\
\hline Kevin & Computer Science & Senior & M & United Kingdom \\
\hline Lucas & Computer Science & Mid & M & United Kingdom \\
\hline Micheal & Psychology & Senior & M & Ireland \\
\hline Jessica & Informatics & Early & $\mathrm{F}$ & USA \\
\hline Daisy & Design & Mid & $\mathrm{F}$ & United Kingdom \\
\hline Beth & Social Science & Early & $\mathrm{F}$ & United Kingdom \\
\hline Enzio & Design & Early & M & Belgium \\
\hline Mary & Design & Early & $\mathrm{F}$ & Belgium \\
\hline Holly & Design & Student & $\mathrm{F}$ & The Netherlands \\
\hline Dion & Design & Student & M & The Netherlands \\
\hline Thomas & Computer Science & Junior Developer & M & Sweden \\
\hline Jarod & Computer Science & Junior Developer & M & United Kingdom \\
\hline Lisa & Computer Science & Mid & $\mathrm{F}$ & Canada \\
\hline Katie & $\mathrm{HCI}$ & Mid & $\mathrm{F}$ & Australia \\
\hline
\end{tabular}

Table 1. Participant Information

Interviews

We iteratively developed a semi-structured interview schedule [47] which consisted of open-ended questions and prompts on: 1) experience in dementia research, 2) experience with institutional ethics processes, 3) technological ethics, 4) power relationships, 5) personal relationships with people with dementia, 6) research impact, and 7) exit strategies. Five of the authors carried out these interviews, lasting from 45 minutes to 1 hour 10 minutes. Interviews were carried out in person where possible, but were otherwise carried out over video calls. All interviews were audio-recorded and transcribed in full.

\section{Data analysis}

With our research approach informed by Belenky et al.'s connected knowing [7], we agreed that Thematic Analysis (TA) [16] was a complementary analytic approach to organise our dataset. With a large dataset (22 interviews 
with an average length of 50 minutes), we utilised multiple coders (3) within the research team in order to avoid bias [10]. Throughout the project, we had weekly meetings with the authors to reflect on what we saw in the data, agree on codes, subcategories, and the building of themes. Our analysis followed a four-step process. First, the three authors who conducted the TA generated codes as labels that considered our research question - for example, 'explaining the use of data', 'learning by observing', and 'novelty not always necessary'. For consistency, the first author went over every interview and compared what was coded by the other two authors to ensure sufficient concordance [71]. Our second round saw us organising codes into potential themes over a Skype call with the authors. The benefit of having multiple coders became relatively apparent in this second round. We gained multiple perspectives and had opportunities to address disagreements and reflect on the themes that had been generated throughout our analysis. In our third step, we started to identify if themes were meaningful to the research question and how they reflected on our conversations throughout the study. Finally, our fourth step was defining the name of our themes as they became interlinked with one another, and giving an overall structure to our analysis.

\section{FINDINGS}

Our findings centre around two overarching themes that describe researchers' reflections on ethical dilemmas and emergent practices in their research. Our first theme, considers the guidelines vs situated practice that explore the different tensions that arise between institutional protection, and recognition/acknowledgement of the person living with dementia. Our second theme emotion and everyday experiences explores the relationships researchers establish with participants, and how researchers initiate and maintain relational approaches. For clarity, we refer to the participants we interviewed as researchers in the rest of the paper, as all of them engage in research to one degree or another.

\section{Guidelines vs situated practice}

Researching under a culture of ethical 'protectionism' caused significant tension when working in socially-oriented research, which our participants described as requiring more flexibility. To this point, the following subthemes describe the ethical challenges researchers face, including a sense of over-protection of participants, and a lack of practical guidance from ethical review boards as to how to navigate ongoing ethical challenges through the research.

\section{Subjectivity and relativity in ERBs}

Researchers highlighted a range of experiences with ERBs that were tied to geographical, cultural, and institutional contexts. Beth expressed how, in the Netherlands, person-centered care is recognised as standard practice, and her ERB provided her with the opportunity to explain the value of possible technologies, and worked with her towards approval of her application. On the other hand, Verna's ERB in Singapore, considers "technology that's implemented into a care home to be a medical device". Because of this, the technology and its ethical review is evaluated much more stringently than might be appropriate. Verna further highlights struggles about whether "engagement activities for people living with dementia [can be considered] a medical device". As soon as the research is being done in a hospital setting, the ERB considered it to be a medical device - "That's like calling a ball used in therapy a medical device". This miscategorisation of aesthetic or pleasurable experiences as an intervention in healthcare indicates that technology has to "make the person better" - as judged by biomedical standards.

The makeup of an ERB can also lead to a biomedical view. Michael says he found significant difficulties getting ethics approved, as his relevant Clinical Research Committee, was "run by mostly medics". Though ERBs try to have people with experience in particular areas, due to the specialisation of research, it is not always possible to have a committee with expertise in dementia from both a person-centered and design angle. Niamh, part of the ethics committee at her university, explains that "you do not know who is going to get your proposal". Perhaps because of the breadth of expertise on the committee, decisions may lack "discernment," as ERBs are perceived as taking a "one size fits all ethics... to be obstructive". Isla reflects on 'one size fits all ethics' when working on an application to recruit from NHS (National Health Service, UK) care homes to take part in a low-risk, qualitative design study exploring the support of intergenerational contact between young people and people living with dementia through technology. She explains that her proposal got "bounced to the NHS ethics" and after a considerable amount of time approval was refused. The medical ethics committee could not see the "benefits of involvement", but instead focused on the risks concomitant with cognitive decline, and the need for protection above inclusion. This, to her, seemed to go against the model of person-centred care which the NHS prizes [69].

Researchers noted that their own experience in the area was not considered in reviews. Thomas expressed that while he thinks ERBs see "the benefit in [the research]", that 'trust is lacking' towards the researcher. Verna describes her collaboration with care homes as being about partnerships built from trust. Similarly, Kevin proposes that ethical review forms should create a collaborative bond between the researcher and the ethics committee. Enzio suggested that ethical approval forms should give the committee information to give them reassurance that the researcher has the support and knows what they are doing such as: "Is 
there a senior researcher? Who is the junior researcher? What's the experience?" Overall, our participants sought a reciprocal relationship with their ERBs, where they could seek support, advice and collaborate in a discursive manner, rather than be judged for their ethical practices or denied approval entirely after a significant amount of time and effort has been expended. Beyond this, our participants also sought the freedom to pursue and maintain an equal relationship with their participants - a task which also became contentious when framed against biomedical ethics.

\section{Recognition of participants' contribution}

Researchers placed importance on acknowledging their participants' contributions to their research. In his own design research, Dion mentioned a lack of recognition from other researchers that caused a domino effect, putting participants off from taking part: "I noticed there was this kind of, almost fatigue [from the carers], that they have seen all these researchers come by, especially many students who make these prototypes. They test it, it is all nice... but then they disappear. There is nothing that remains."

When Dion explained his research to the participants, the participants said "Why do we need this? Why can't there be something that stays?" This illustrates the importance of clearly articulating what participants should expect throughout the study, as well as acknowledging their participation in an appropriate way. Typically, researchers will often pay their participants with vouchers for their time. However, Thomas stated that in care homes, money "doesn't really work in this setting... money does not hold too much value there". If the traditional approach to compensation does not work in this setting, we must consider other ways to compensate people with dementia for their participation. One approach is to offer participants the technology that we build. In our conversation with Niamh, she discussed a different approach to disseminate research to be useful for the participants: "So, we co-designed a toolkit with them and left them with the toolkits and left research materials, and things, when we went over...they were really taking time out of their- you know, some of them were travelling up to three hours just to get there. Three hours, three hours back, just to come early to come and do these things."

Though this approach works well with some research, other HCI projects focus on initial exploration, where prototypes are not fit to withstand long time use without continuous check-ups and fixes. Echoing this, Isla shared concerns "of anxiety and failure" if the technology breaks, and conflict towards the technology "may break in a year or two." Another way researchers give back and recognise participants' contributions is through ceremonies or events to commemorate and celebrate participation. Through our interviews, Louise and Daisy reflected on using the term 'celebration' and the act of giving as a way to value their participants work through the study. Daisy sees the celebration as " $a$ way of celebrating the lives of the participants that have helped develop whatever you've found". Louise reflects on creating personalised gifts and celebrating research with those involved through her $\mathrm{PhD}$ study: "For them, maybe I just came in, but for me, it was a very meaningful relationship. I probably just didn't want it to end, to be honest." Regardless of how we acknowledge contribution, we should recognise participants as individuals who have contributed to the research and that their knowledge, experience, and time are valuable and valued. Again, however, some ways of doing this can raise issues with ERBs.

\section{Protection vs acknowledgement}

Keeping participants anonymous is standard ethical practice [70]. Researchers commonly use pseudonyms, and in photographs, blur faces to ensure data collected cannot be traced back to the original participants. Throughout the interviews, researchers expressed an understanding of safety and respect to the participants when anonymising data. However, Kevin noted that this approach seems to be more about "making sure we stay within the university's insurance" and less about "avoiding harm to participants". Daisy mentions that anonymisation works when participants "might not want their [real] name [used]", but when participants want to be recognised for their contributions, challenges can arise.

Several researchers commented on the challenges they have had when participants want to be acknowledged as co-creators. Lucas reflected on previous work where he had participants ask "We have done this work... Can we have some credit for it? Can our names appear in the research?" But as it stands, "they can't, because [the] ethics board says it must be anonymised." In response to this, some researchers have aimed to "write in' this possibility to their ethical applications to allow for its occurrence. Daisy highlights further tensions here: when it takes the form of prioritising protection, institutional protection can further add to the feeling of "dementia rob[bing] people of their dignity, their individuality and their lived life." Through Daisy's awareness of working with people living with dementia, she believes that "to make them anonymous or a number is robbing them of their dignity." Dion considers appropriate ways to acknowledge the person living with dementia's contribution through remembering a photoshoot for a care organisation's magazine: "[the photographer] came by to take some pictures and ask for permissions, and I was with the participant, interacting, but it was a bit fake, of course." Dion reflects on this moment, saying the participant "was enjoying it", and was "laughing" during the activity. The participants were particularly "proud that 
she could be on the pictures, and in the article of the magazine".

A growing number of publications include people with dementia as authors to recognise their contributions. Enzio named a UK institution that hired participants as research collaborators and through this, ensured they were given authorship of subsequent publications: "I think this in-between solution is great. If you have a participant who is joining you for some time, Then they are equal to you as an author of work or papers." Jessica also mentions Dementia Enquirers, a group "who have a project where people with dementia are coming up [with research studies] and that have [their own] ethics [guidelines]. " Recognising participants by opening up authorship ensures participants are influencing the research agenda, in contrast to the current standard practice of anonymisation of participants. However, the ACM code of authorship states that authors must "have participated in drafting and/or revision of the manuscript" [1]. We should question whether the ACM model should shift towards a contributorship model, in which contributions towards the project are credited rather than academic writing.

\section{Emotion and everyday experiences}

Through our interviews, researchers described various views on both the ideal and realistic impact of their work. In this theme, we unpack the subjective role of time in research impact, and the importance in building and continuing relationships that hold meaning as part of the research.

\section{Time and pacing}

Researchers noted tensions arising when the timeline of a research project does not align with researchers' best practices. There are differing views on what should be emphasised: one perspective, stemming from participatory design and action research [36], espouses allowing relationships to develop slowly over time, while the other emphasises the value of a swift design process where visible progress is made in step with technology development [37]. From our interviews, it was common to hear how important it was to researchers to create relationships throughout the research. Isla mentioned that "we should be taking our time, and doing things mindfully and treating every single person as a person". At odds with timelines that rush data collection for a deadline, several researchers emphasised a more relational approach that takes time and care throughout the entirety of the study, up to its ending. This model bears more resemblance to person-centred care, which "...brings into focus the uniqueness of each person, respectful of what they have accomplished and compassionate to what they have endured." [25] Michael comments on how researchers should be considering continuity, and not be "drop [ping] in and out of care homes or peoples lives for two or three months in order to get data to write a paper". He explains that it is unreasonable "to jump into people's lives... and come back and expect them to be open-armed and welcoming us again three months later." In situations where this is not feasible as part of the research, Isla suggests "go and have a coffee or work to their schedule, I guess. They are the most important part of our research."

While Isla and Michael express the need to take more time in the research process, Lucas mentioned he finds design iteration to be "too slow of a process". While he agrees relationships should take as much time as they need to develop, once the study moves to iteration and design, it should speed up. Lucas discusses the frustration participants may experience if they are expecting something to be built: "meeting and chatting with someone for a couple of hours each week can feel like not much is happening. Especially if you come back and that thing you said you would do hasn't been altered, and maybe it has to be discussed again next week". Once design iteration starts, researchers should engage and involve people living with dementia in the study as much as possible and through design responses which "show people that you are taking feedback seriously". In particular, when designing with people living with dementia, there is a distinct progression in the diagnosis over time. If we prolong the research study, "what [the person with dementia] needed at the start ... might be different from what they wanted at the end of it". These insights offer questions concerning the trajectory of a project, including explicitly planning for the time it takes to grow and support meaningful relationships with research participants. This is especially important with people living with dementia, as understanding each individual's communication abilities can support better engagement in research as well as better research outcomes.

\section{Understanding impact}

Bringing technology into research offers opportunities for meaningful engagement, but also ethical challenges relating to the robustness and longevity of technology when the project ends. In our interviews, researchers offered different perspectives on what is most important: the technology itself working, or the meaning and the relationships that they engender. Dion notes that it is "difficult to do these long-term solutions", and while it is easy to say "we need to leave something behind", the technology still needs "technical support.. because they break down every week or so." Isla reflects on a colleague who had difficulties maintaining technology after the study had ended. The researcher "guaranteed [the device] to last for the year of the study.. and will fix it [throughout the year]". While the researcher appropriately managed expectations of the study with participants, "one of the participants hung on to the technology for years and found it was helping [her quality of life]". As it broke, the participant asked for help to fix it, but "the research was gone. The funding was gone." As 
researchers, Isla suggests we have a responsibility to anticipate and be "upfront and say there is a natural lifespan to some of these technologies". One direction researchers take is by thinking about longevity in ways other than the lifespan of the technology itself. Thomas highlights how the value in participants taking part in the research is the opportunity to have a say "on the new social direction of that [community]".

Emily expresses building a sense of the lifespan of media or other possible technologies into her research. The couple she worked with, "had pictures of things they made together [throughout the research]... and that meant a lot." By placing her participants as the focal point who drove the research, the research itself became a significant event for them. Emily remarks that technology "doesn't have to be cutting edge to be meaningful, and to do something poetic and powerful". In this way, it's clear that researchers should consider that technology alone does not hold any value; it's the relationships and experiences it creates. However, there can be an expectation of, and value, associated with longevity. Martin shared a story about his grandad designing gifts for his grandma:

"My grandma looked after my grandpa through his dementia until he sadly passed away. One Christmas, he created a beautiful Nativity scene. On the backdrop was LED lights that resembled the stars and was powered by a battery. On the back of the nativity scene, my grandpa wrote: "My love lasts as long as the battery". Every year, Martin's grandma brings out the scene for a few days and places the very same battery that she has had for over 20 years to see if it still works ("to this day, it still does").

Kevin expressed ethical value in working with businesses to help and maintain a product after the end of a project. Kevin says "grants only ever get you so far... [researchers] have got to come up with a value proposition". By bringing in industrial connections, researchers can find ways to "reinvest [money into the product] and keep the stuff going". Within these more extensive projects, more comprehensive sets of skills were implicated, involving complexities on its own. Kevin iterates by working with "business people, venture capitalists", his study has the opportunity to find the best way for technology to get to the market, where, ostensibly, it will find further impact. Kevin further expresses that research should aim to "build robust software that can result in spin-offs or commercial partnerships to get to the next stage". However, this can be a contested space with participants, particularly carers, concerning how long it takes for design products to arrive on the market, and what the price might be when it gets there. This further highlights the need for making the design and research process as legible as possible for participants.

\section{Ecology of (self)care}

Emotions and their influence were discussed by several of our participants. Enzio reflected that "building relationships between researchers and participants help to appropriate the technology around the person living with dementia and their ecology of care". Working primarily with students, their emotions influenced the way they formed relationships and engaged with the research. Seeing his students sensitively attending to lived experience, Enzio realised that "this would not have happened if they just made something for a generic 'person with dementia' without having this personal relationship".

Louise, who works on a study in a care home, reflected on learning from assuming a caregiver's experience. Over five years, Louise talks about one participant who "used to be engaged". Over time, as "her dementia progressed", that participant became "very shy". That change in personality and expression gave Louise "the best sense of what it might be like to watch a loved one in that process and try to bring them back." While focused on imagining a caregiver's lived experience, it changed Louise's view of "being quite critical" of people trying to 'bring back' their loved one's memory. Having spent more time on the project, Louise had a more in-depth understanding of "how it can be really difficult" to see someone go through a diagnosis of dementia. Louise's experience of 'unexpected' emotion is reflected on as emotionally significant. As researchers, we have "the luxury" to reflect on the lived experiences we are a part of. Having time to reflect allows researchers to better understand the emotional nature of the work we are doing. Working in dementia care comes with complexities in that participants may pass away, or that their dementia will likely progress. Katie expresses that this can represent "big emotional stress for researchers". Dion highlights the ethical and moral complexities of "hav[ing] observational data" from a participant who had passed away before any publication. Similar to many other academics, Dion echoed the struggles of what to do in this situation: "Do you use the data or not? How do you mention this in a paper? Those are things that I don't know how to handle actually. I found it very difficult. What do you do with it?"

In this instance, Dion particularly struggles between his emotions influencing his choice on whether his work be published. However, it is likely that simply not talking about the work will not divert the conflicted emotions stemming from having carried out the research in question [89]. If we are moving towards reflexive practices in HCI, these seemingly personal experiences from researchers should be integrated into the empirical nature of our work [76]. Self-care is similarly important: Mary recommends to "be true to your personality and feelings" and to make "time to talk about the experience, even if this [has] no 
specific function in the research". Researchers should take time to reflect and discuss the experiences they have had through their research; in doing this, they may lay down healthier, more open and more empathetic practices for researchers who may follow in their shoes.

Researchers' feelings were that ERBs continue to over-protect participants, causing tension with the involvement of participants throughout the research, including not being acknowledged for their contributions. Isla remarks "we should be as present as possible...the more open and almost kind and loving you can be towards someone, the better, without compromising your self-care”. Following the 'Butterfly Method' of emphasising presence and emotional intelligence, bringing this human [45], connective element to the forefront of ethical design practices may be an essential step in moving this research space forward.

\section{DISCUSSION}

Our findings indicate that ethical tensions arise when researchers find themselves conflicted between the ethical guidelines they need to comply to and the specifics of the research, such as participant characteristics, relationships that have developed over the course of the study, the role technology has taken in the participants' lives, and the researchers' own definition and understanding of what it means to have long lasting impact [60]. We described how researchers ethically navigate the contrast between ethics in theory and practice, ultimately requiring an 'in the moment' investment in the integrity of the relationship with both participants and backing institutions. Below, we discuss how our findings add to and contrast with previous work in this field and suggest future directions for HCI researchers.

Participants discussed challenges in maintaining boundaries in participant-researcher relationships. Working within an experience-centred design framework, Balaam et al. [4] note the need for designers and researchers to be more accepting of how we engage and manage emotion in our work. Through engaging with emotion, we must consider boundaries as subjectively based on contextual knowledge of the research relationships. From the reflections presented in our findings, it is evident that emotion is an integral part of much socially-oriented HCI research, and thus must also be taken into account in considering ethics. Furthermore, our interviews indicated participants wish for more reflexivity in the ethical review process, where researchers can seek support, advice and collaborate in a discursive manner. Researchers have much to communicate back to ERBs in terms of how to ensure the inclusion of vulnerable populations, which past research has argued is an ethical and moral design outcome to strive for [77]. By clarifying expectations for participants, and knowing when and how to involve participants in the research, we can support better engagement in research as well as better research outcomes.
However, the emotionally engaging nature of this work and empathetic response evident in the findings suggests the importance of supporting care practices - self-care and otherwise - as part of the research design.

\section{Towards flexible ethics for sensitive $\mathrm{HCl}$ research}

This final section suggests a set of future directions guided by the participants' reflections on working with people with dementia. Although ethical practices in HCI have been a focus for many years, we would posit that these directions are the first to be a) focused on working with marginalised populations, and b) informed by a focused and empirical research study. These research directions, though based on work in dementia, have applicability to people working with other populations that are considered vulnerable, including work at the end-of-life and with people with short and long term cognitive impairment. Despite the applicability of some of these points to other areas, it is important for researchers in other areas to contribute their experiences in future work.

\section{Designing for research technologies' end of life}

While not typically regulated by ERBs, researchers saw the importance in the longevity of their research projects, posing concerns regarding what happens if/when the technology involved malfunctions or stops working. Our conversations with Emily highlighted the fact that, "technology breaks, it dies, change happens, but that just mirrors life." However, this does not mean the technology needs to be boxed away forever. While many reflections detailed the challenges and struggles in sustaining technology, designing for practices surrounding the 'death' of the technology is a novel idea which can become a moment to celebrate and reflect on the life of the technology and what it represented. As researchers, we should consider how we can retain the meaning associated with the celebration within the object long after the technologies function stops, or a service is no longer supported. ERBs should take into consideration what it means for the participants once the project ends. By ERBs and researchers working closely with the participants pre-study, it allows for ethically-considered 'endings' for projects, and an engaged debriefing process.

In a similar vein, while our findings and the above discuss the end of life for the technology, there is a lack of discussion around best practices for ending research, giving post-support or guidance for participants such as advising them towards similar market solutions, resources that are community-driven such as charities provide "places to go and things to do" for families living with dementia [46]. A key issue discussed in the HCI community is the push towards innovative project outcomes. Meurer et al. [62] discusses the problems of innovation and its impact on sustainability. The drive to create novel research not only puts pressure that forces solutions that may not be 
appropriate for the community, but research may be ill-judged on funding for continued support after the project ends.

\section{Designing for Impact}

Participants had different views of what it means to have impact. For some, it is a moment of real connection rather than the technology that's created [91]. In our findings, this often correlated with frustrations with technology not being robust or lacking longevity - for example, Louise discussed her frustrations of not leaving technology behind after a study is over. In exploratory work, there is not enough time to develop robust products that can continue to stay with the participants. With not enough time, frustrations participants have with the technology may never be fixed. Lucas remarks on this further: he sees irritation from participants when a bug is not fixed as participants may feel their efforts were unacknowledged. This echoes Vines et al. [88], who describes ethical difficulties in using Google Glass, a technology supported by a large corporation, which still had bugs typically found in prototypes. This created frustrations with the participants ranging from poor battery life to Google sporadically updating the system in spite of participants' wishes to the contrary. However, as seen in our analysis, researchers can place focus on the things that matter to participants through other means, and through cultivating reciprocal relationships.

For others researchers, impact relied on whether participants continued using their technologies, and in developing successful industrial spin-offs to sustain their research. Kevin suggested that researchers should consider business link-ins when writing grants and that "it is all about partnerships." Involving businesses into the start of research can still position participants at the forefront of the research, and allow value in creating technology that may outlast the study's timeline. This can also fall into similar problems when funding ends. Returning to Vines et al [88], two years after the Google Glass project, Google "stalled their support", and any prospect of future development "into a product [was] diminished". In this way, even when working with large and well-funded businesses, support may only continue if it seems profitable. A recent CSCW workshop discusses the appropriate relationship between research and industry in terms of industry funding [42]: we encourage the continuation and expansion of this dialogue to discuss other facets of collaborations such as those that emerged in our work.

\section{Designing for research clarity}

Researchers felt that the institutional ethical application process needs to be developed further. This poses the question: what can researchers do to ensure ERBs are more dynamic and reflexive when evaluating research which seeks to design or innovate in sensitive settings? From our findings, researchers found tensions when working under a culture of ethical 'protectionism'. ERBs focus on protection tends to focus on the individual as opposed to the community. As researchers who are increasingly engaging in socially-oriented research, it's integral for ERBs to do the same. It is evident within our analysis that participant involvement in design is central to most of the ethical approaches of the researchers. However, the extent to which we involve our participants and the implications of this remains a contested and under-examined issue. As participant Jessica discussed, engaging with advocates outside of HCI, such as the Dementia Enquirers [23], ensures that research agendas are more closely aligned with the needs of the population, thus "helping improve the quality, relevance and ethical conduct of dementia research". Ensuring our research designs are rooted in participant-led agendas can contribute to ethically engaged research impact. Involving the community to be part of the ethical review board, not only contextualises a deeper understanding of what work is sensitive, and what is not, it also articulates the interests and priorities of the individuals the research will impact $[8,28,79]$. For ERBs, they must consider how they can create tools to promote conversation and inclusion of community members, and for researchers, how we explain our research processes and priorities - both to participants, the ecology of care and to ERBs.

\section{CONCLUSION}

Ethical Review Boards, in prioritising the protection of human subjects, can inadvertently bar the full inclusion of people living with dementia in socially-oriented research. This being so, researchers in the field have gained a variety of insight into the ethical complexities when it comes to working in HCI. This paper provides a reflective analysis of the accounts of 22 researchers working in dementia design research. Our analysis of interviews produced two overarching themes: guidelines vs situated practice, and emotion and everyday experiences. We proceed from our findings to emphasise directions that are applicable in all HCI research that seeks to work with marginalised populations: designing for technological end of life, re-framing impact and aiming for research clarity.

\section{ACKNOWLEDGEMENTS}

We would like to thank the participants for their support during the study. This work was funded by EPSRC (EP/L016176/1) (https://epsrc. ukri.org/), and in part by grant 90REGE0008, US. Admin. for Community Living, NIDILRR, Dept. of Health \& Human Services, and STW VIDI grant 016.128.303 of The Netherlands Organisation for Scientific Research (NWO). Data supporting this publication is not openly available due to confidentiality consideration - $\underline{\mathrm{dx}}$.doi.org/10.25405/data.ncl.11494395.

\section{REFERENCES}

[1] ACM. Criteria for Authorship. Retrieved September 
20, 2019 from

https://www.acm.org/publications/policies/authorship

[2] Jan Philipp Albrecht. 2016. How the GDPR Will Change the World. European Data Protection Law Review (EDPL), 3: 287-289.

[3] Arlene Astell, Sarah Smith, and Philip Joddrell. 2019. Using Technology in Dementia Care: A Guide to Technology Solutions for Everyday Living. Jessica Kingsley Publishers.

[4] Madeline Balaam, Rob Comber, Rachel E. Clarke, Charles Windlin, Anna Ståhl, Kristina Höök, and Geraldine Fitzpatrick. 2019. Emotion Work in Experience-Centered Design. In Proceedings of the 2019 CHI Conference on Human Factors in Computing Systems (CHI '19), 602:1-602:12. https://doi.org/10.1145/3290605.3300832.

[5] Shaowen Bardzell and Jeffrey Bardzell. 2011. Towards a Feminist HCI Methodology: Social Science, Feminism, and HCI. In Proceedings of the SIGCHI Conference on Human Factors in Computing Systems (CHI '11), 675-684. https://doi.org/10.1145/1978942.1979041.

[6] Marguerite Barry, Kevin Doherty, Jose Marcano Belisario, Josip Car, Cecily Morrison, and Gavin Doherty. 2017. mHealth for Maternal Mental Health: Everyday Wisdom in Ethical Design. In Proceedings of the 2017 CHI Conference on Human Factors in Computing Systems (CHI '17), 2708-2756. https://doi.org/10.1145/3025453.3025918.

[7] Mary Field Belenky, Blythe McVicker Clinchy, Nancy Rule Goldberger, and Jill Mattuck Tarule. 1986. Women's ways of knowing: The development of self, voice, and mind. Basic Books, New York, NY, US.

[8] Kirsten Bell and Denielle Elliott. 2014. Censorship in the name of ethics: critical public health research in the age of human subjects regulation. Critical Public Health 24, 4: 385-391. https://doi.org/10.1080/09581596.2014.936727.

[9] Steve Benford, Chris Greenhalgh, Bob Anderson, Rachel Jacobs, Mike Golembewski, Marina Jirotka, Bernd Carsten Stahl, Job Timmermans, Gabriella Giannachi, Matt Adams, Ju Row Farr, Nick Tandavanitj, and Kirsty Jennings. 2015. The Ethical Implications of HCI's Turn to the Cultural. $A C M$ Trans. Comput.-Hum. Interact. 22, 5: 24:1-24:37. https://doi.org/10.1145/2775107.

[10] Lynda Berends and Jennifer Johnston. 2005. Using multiple coders to enhance qualitative analysis: The case of interviews with consumers of drug treatment. Addiction Research \& Theory 13, 4: 373-381. https://doi.org/10.1080/16066350500102237.

[11] Pernille Bjorn, Casey Fiesler, Michael Muller, Jessica Pater, and Pamela Wisniewski. 2018. Research Ethics
Town Hall Meeting. In Proceedings of the 2018 ACM Conference on Supporting Groupwork (GROUP '18), 393-396. https://doi.org/10.1145/3148330.3154523.

[12] Susanne Bødker. 2006. When Second Wave HCI Meets Third Wave Challenges. In Proceedings of the 4th Nordic Conference on Human-computer Interaction: Changing Roles (NordiCHI '06), 1-8. https://doi.org/10.1145/1182475.1182476.

[13] John Bond. 1992. The medicalization of dementia. Journal of Aging Studies 6, 4: 397-403. https://doi.org/10.1016/0890-4065(92)90020-7.

[14] Rita Maldonado Branco, Joana Quental, and Óscar Ribeiro. 2017. Personalised participation: an approach to involve people with dementia and their families in a participatory design project. CoDesign 13, 2: 127-143. https://doi.org/10.1080/15710882.2017.1310903.

[15] Rens Brankaert, Gail Kenning, Daniel Welsh, Sarah Foley, James Hodge, and David Unbehaun. 2019. Intersections in HCI, Design and Dementia: Inclusivity in Participatory Approaches. In Companion Publication of the 2019 on Designing Interactive Systems Conference 2019 Companion (DIS '19 Companion), 357-360. https://doi.org/10.1145/3301019.3319997.

[16] Virginia Braun and Victoria Clarke. 2006. Using thematic analysis in psychology. Qualitative Research in Psychology 3, 2: 77-101. https://doi.org/10.1191/1478088706qp063oa.

[17] Dawn Brooker. 2003. What is person-centred care in dementia? Reviews in Clinical Gerontology 13, 03: 215-222. https://doi.org/10.1017/S095925980400108X.

[18] Dawn Brooker and Isabelle Latham. 2015. Person-Centred Dementia Care, Second Edition: Making Services Better with the VIPS Framework. Jessica Kingsley Publishers.

[19] Amy S. Bruckman, Casey Fiesler, Jeff Hancock, and Cosmin Munteanu. 2017. CSCW Research Ethics Town Hall: Working Towards Community Norms. In Companion of the 2017 ACM Conference on Computer Supported Cooperative Work and Social Computing (CSCW'17 Companion), 113-115. https://doi.org/10.1145/3022198.3022199.

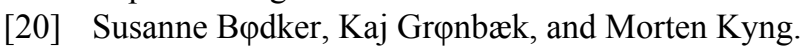
1995. Cooperative Design: Techniques and Experiences From the Scandinavian Scene. In Readings in Human-Computer Interaction, RONALD M. Baecker, JONATHAN Grudin, WILLIAM A. S. Buxton and SAUL Greenberg (eds.). Morgan Kaufmann, 215-224. https://doi.org/10.1016/B978-0-08-051574-8.50025$\mathrm{X}$.

[21] Willig Carla. 2013. Introducing Qualitative Research 
In Psychology. McGraw-Hill Education (UK).

[22] Hilary Davis and Jenny Waycott. 2015. Ethical Encounters: HCI Research in Sensitive and Complex Settings. In Proceedings of the Annual Meeting of the Australian Special Interest Group for Computer Human Interaction (OzCHI '15), 667-669. https://doi.org/10.1145/2838739.2838834.

[23] DEEP. Dementia Enquirers. DEEP. Retrieved September 20, 2019 from https://www.dementiavoices.org.uk/dementia-enquire rs/.

[24] Jan Dewing. 2007. Participatory research: A method for process consent with persons who have dementia. Dementia 6, 1: 11-25. https://doi.org/10.1177/1471301207075625.

[25] Jan Dewing. 2008. Personhood and dementia: revisiting Tom Kitwood's ideas. International Journal of Older People Nursing 3, 1: 3-13. https://doi.org/10.1111/j.1748-3743.2007.00103.x.

[26] Paul Dourish. 2014. Reading and Interpreting Ethnography. In Ways of Knowing in HCI, Judith S. Olson and Wendy A. Kellogg (eds.). Springer New York, New York, NY, 1-23. https://doi.org/10.1007/978-1-4939-0378-8_1.

[27] Sue Eckstein (ed.). 2003. Operational guidelines for ethics committees that review biomedical research. In Manual for Research Ethics Committees. Cambridge University Press, Cambridge, 505-515. https://doi.org/10.1017/CBO9780511550089.069.

[28] Sarah J. L. Edwards, Richard Ashcroft, and Simon Kirchin. 2004. Research ethics committees: differences and moral judgement. Bioethics 18, 5: 408-427.

[29] Melanie Ehrenkranz. Men Try to "Redefine" Sexual Consent With Blockchain. Gizmodo. Retrieved September 20, 2019 from

https:/gizmodo.com/men-try-to-redefine-sexual-cons ent-with-blockchain-1821964907.

[30] Ruth Elvish, Ian James, and Derek Milne. 2010. Lying in dementia care: an example of a culture that deceives in people's best interests. Aging \& Mental Health 14, 3: 255-262. https://doi.org/10.1080/13607861003587610.

[31] Ilker Etikan. 2016. Comparison of Convenience Sampling and Purposive Sampling. American Journal of Theoretical and Applied Statistics 5: 1. https://doi.org/10.11648/j.ajtas.20160501.11.

[32] Sam Fazio, Douglas Pace, Janice Flinner, and Beth Kallmyer. 2018. The Fundamentals of Person-Centered Care for Individuals With Dementia. The Gerontologist 58, suppl_1: S10-S19. https://doi.org/10.1093/geront/gnx122.

[33] Sarah Foley, John McCarthy, and Nadia Pantidi. 2019. The Struggle for Recognition in Advanced
Dementia: Implications for Experience-Centered Design. ACM Transactions on Computer-Human Interaction 26, 6: 1-29. https://doi.org/10.1145/3359594.

[34] Sarah Foley, Nadia Pantidi, and John McCarthy. 2019. Care and Design: An Ethnography of Mutual Recognition in the Context of Advanced Dementia. In Proceedings of the 2019 CHI Conference on Human Factors in Computing Systems (CHI '19), 610:1-610:15. https://doi.org/10.1145/3290605.3300840.

[35] Sarah Foley, Daniel Welsh, Nadia Pantidi, Kellie Morrissey, Tom Nappey, and John McCarthy. 2019. Printer Pals: Experience-Centered Design to Support Agency for People with Dementia. In Proceedings of the 2019 CHI Conference on Human Factors in Computing Systems (CHI '19), 404:1-404:13. https://doi.org/10.1145/3290605.3300634.

[36] Marcus Foth. Participatory Design and Action Research: Identical Twins or Synergetic Pair? .

[37] Martin Fowler and Jim Highsmith. 2001. The Agile Manifesto. Dr. Dobb's. Retrieved December 24, 2019 from

http://www.drdobbs.com/open-source/the-agile-manif esto/184414755.

[38] Christopher Frauenberger, Amy S. Bruckman, Cosmin Munteanu, Melissa Densmore, and Jenny Waycott. 2017. Research Ethics in HCI: A Town Hall Meeting. In Proceedings of the 2017 CHI Conference Extended Abstracts on Human Factors in Computing Systems (CHI EA '17), 1295-1299.

https://doi.org/10.1145/3027063.3051135.

[39] Batya Friedman. 1996. Value-sensitive Design. interactions 3, 6: 16-23. https://doi.org/10.1145/242485.242493.

[40] Kenneth J. Gergen. 1985. Social Constructionist Inquiry: Context and Implications. In The Social Construction of the Person, Kenneth J. Gergen and Keith E. Davis (eds.). Springer, New York, NY, 3-18. https://doi.org/10.1007/978-1-4612-5076-0_1.

[41] Bernard Gert and Joshua Gert. 2017. The Definition of Morality. In The Stanford Encyclopedia of Philosophy (Fall 2017), Edward N. Zalta (ed.). Metaphysics Research Lab, Stanford University. Retrieved September 17, 2019 from https://plato.stanford.edu/archives/fall2017/entries/m orality-definition/.

[42] Critical Platform Studies Group, Lilly Irani, Niloufar Salehi, Joyojeet Pal, Andrés Monroy-Hernández, Elizabeth Churchill, and Sneha Narayan. 2019. Patron or Poison?: Industry Funding of HCI Research. In Conference Companion Publication of the 2019 on Computer Supported Cooperative Work and Social Computing (CSCW '19), 111-115. 
https://doi.org/10.1145/3311957.3358610.

[43] Maurice Hamington. 2019. Integrating Care Ethics and Design Thinking. Journal of Business Ethics 155, 1: 91-103. https://doi.org/10.1007/s10551-017-3522-6.

[44] Niels Hendriks, Liesbeth Huybrechts, Andrea Wilkinson, and Karin Slegers. 2014. Challenges in Doing Participatory Design with People with Dementia. In Proceedings of the 13th Participatory Design Conference: Short Papers, Industry Cases, Workshop Descriptions, Doctoral Consortium Papers, and Keynote Abstracts - Volume 2 (PDC '14), 33-36. https://doi.org/10.1145/2662155.2662196.

[45] James Hodge, Madeline Balaam, Sandra Hastings, and Kellie Morrissey. 2018. Exploring the Design of Tailored Virtual Reality Experiences for People with Dementia. In Proceedings of the 2018 CHI Conference on Human Factors in Computing Systems - CHI '18, 1-13. https://doi.org/10.1145/3173574.3174088.

[46] James Hodge, Kyle Montague, Sandra Hastings, and Kellie Morrissey. 2019. Exploring Media Capture of Meaningful Experiences to Support Families Living with Dementia. In Proceedings of the 2019 CHI Conference on Human Factors in Computing Systems (CHI '19), 423:1-423:14. https://doi.org/10.1145/3290605.3300653.

[47] Joanne Horton, Richard Macve, and Geert Struyven. 2004. Chapter 20 - Qualitative Research: Experiences in Using Semi-Structured Interviews1. In The Real Life Guide to Accounting Research, Christopher Humphrey and Bill Lee (eds.). Elsevier, Oxford, 339-357. https://doi.org/10.1016/B978-008043972-3/50022-0.

[48] Maarten Houben, Rens Brankaert, Saskia Bakker, Gail Kenning, Inge Bongers, and Berry Eggen. 2019. Foregrounding Everyday Sounds in Dementia. In Proceedings of the 2019 on Designing Interactive Systems Conference (DIS '19), 71-83. https://doi.org/10.1145/3322276.3322287.

[49] John Killick Claire Craig. 2012. Creativity and Communication in Persons With Dementia: A Practical Guide. Jessica Kingsley, London.

[50] Tom Kitwood and Kathleen Bredin. 1992. Towards a Theory of Dementia Care: Personhood and Well-being. Ageing \& Society 12, 3: 269-287. https://doi.org/10.1017/S0144686X0000502X.

[51] Mark L Knapp and Judith A Hall. 2013. Nonverbal Communication in Human Interaction. 8th Edition. Retrieved from https://testbank24.com/pdf/Test-Bank-Nonverbal-Co mmunication-in-Human-Interaction-8th-Edition-Kna pp.pdf.
[52] Pia C. Kontos and Gary Naglie. 2007. Expressions of Personhood in Alzheimer's Disease: An Evaluation of Research-Based Theatre as a Pedagogical Tool. Qualitative Health Research 17, 6: 799-811. https://doi.org/10.1177/1049732307302838.

[53] Pia Kontos and Alisa Grigorovich. 2018. Integrating Citizenship, Embodiment, and Relationality: Towards a Reconceptualization of Dance and Dementia in Long-Term Care. The Journal of Law, Medicine \& Ethics 46, 3: 717-723. https://doi.org/10.1177/1073110518804233.

[54] Pia Kontos and Wendy Martin. 2013. Embodiment and dementia: Exploring critical narratives of selfhood, surveillance, and dementia care. Dementia 12, 3: 288-302. https://doi.org/10.1177/1471301213479787.

[55] Amanda Lazar. 2014. Using Technology to Increase Meaningful Engagement in a Memory Care Unit. In Proceedings of the 18th International Conference on Supporting Group Work (GROUP '14), 255-257. https://doi.org/10.1145/2660398.2660433.

[56] Amanda Lazar, Caroline Edasis, and Anne Marie Piper. 2017. A Critical Lens on Dementia and Design in HCI. In Proceedings of the 2017 CHI Conference on Human Factors in Computing Systems - CHI '17, 2175-2188.

https://doi.org/10.1145/3025453.3025522.

[57] Amanda Lazar, Caroline Edasis, and Anne Marie Piper. 2017. Supporting People with Dementia in Digital Social Sharing. In Proceedings of the 2017 CHI Conference on Human Factors in Computing Systems (CHI '17), 2149-2162. https://doi.org/10.1145/3025453.3025586.

[58] V. Leuty, J. Boger, L. Young, J. Hoey, and A. Mihailidis. 2013. Engaging older adults with dementia in creative occupations using artificially intelligent assistive technology. Assistive technology: the official journal of RESNA 25, 2: 72-79. https://doi.org/10.1080/10400435.2012.715113.

[59] Jill Manthorpe and Kritika Samsi. 2016. Person-centered dementia care: current perspectives. Clinical Interventions in Aging 11: 1733-1740. https://doi.org/10.2147/CIA.S104618.

[60] Matts Mattsson and Stephen Kemmis. 2007. Praxis-related research: serving two masters? Pedagogy, Culture \& Society 15, 2: 185-214. https://doi.org/10.1080/14681360701403706.

[61] John McCarthy and Peter Wright. 2007. Technology As Experience. The MIT Press.

[62] Johanna Meurer, Claudia Müller, Carla Simone, Ina Wagner, and Volker Wulf. 2018. Designing for Sustainability: Key Issues of ICT Projects for Ageing at Home. Computer Supported Cooperative Work (CSCW) 27, 3: 495-537. 
https://doi.org/10.1007/s10606-018-9317-1.

[63] Kellie Morrissey and John McCarthy. 2015. Creative and Opportunistic Use of Everyday Music Technologies in a Dementia Care Unit. In Proceedings of the 2015 ACM SIGCHI Conference on Creativity and Cognition (C\&C '15), 295-298. https://doi.org/10.1145/2757226.2757228.

[64] Kellie Morrissey, John McCarthy, and Nadia Pantidi. 2017. The Value of Experience-Centred Design Approaches in Dementia Research Contexts. In Proceedings of the 2017 CHI Conference on Human Factors in Computing Systems (CHI '17), 1326-1338. https://doi.org/10.1145/3025453.3025527.

[65] Kellie Morrissey, Gavin Wood, David Green, Nadia Pantidi, and John McCarthy. 2016. "I'm a rambler, I'm a gambler, I'm a long way from home." In Proceedings of the 2016 ACM Conference on Designing Interactive Systems - DIS '16, 1008-1020. https://doi.org/10.1145/2901790.2901798.

[66] Michael J Muller and Allison Druin. Participatory Design: The Third Space in HCI. 70.

[67] Cosmin Munteanu, Amy Bruckman, Michael Muller, Christopher Frauenberger, Casey Fiesler, Robert E. Kraut, Katie Shilton, and Jenny Waycott. 2019. SIGCHI Research Ethics Town Hall. In Extended Abstracts of the 2019 CHI Conference on Human Factors in Computing Systems (CHI EA '19), pane105:1-panel05:6. https://doi.org/10.1145/3290607.3311742.

[68] Cosmin Munteanu, Heather Molyneaux, Wendy Moncur, Mario Romero, Susan O'Donnell, and John Vines. 2015. Situational Ethics: Re-thinking Approaches to Formal Ethics Requirements for Human-Computer Interaction. In Proceedings of the 33rd Annual ACM Conference on Human Factors in Computing Systems (CHI '15), 105-114. https://doi.org/10.1145/2702123.2702481.

[69] NHS. NHS - Involving people in their own care. Retrieved December 24, 2019 from https://www.england.nhs.uk/ourwork/patient-particip ation/.

[70] Alison Novak. 2014. Anonymity, Confidentiality, Privacy, and Identity: The Ties That Bind and Break in Communication Research. Review of Communication 14, 1: 36-48. https://doi.org/10.1080/15358593.2014.942351.

[71] Lorelli S. Nowell, Jill M. Norris, Deborah E. White, and Nancy J. Moules. 2017. Thematic Analysis: Striving to Meet the Trustworthiness Criteria. International Journal of Qualitative Methods 16, 1: 1609406917733847. https://doi.org/10.1177/1609406917733847.

[72] Chaim Noy. 2008. Sampling Knowledge: The
Hermeneutics of Snowball Sampling in Qualitative Research. International Journal of Social Research Methodology 11, 4: 327-344. https://doi.org/10.1080/13645570701401305.

[73] Femi Oyebode and Darren Shickle. 2005. The Mental Capacity Act 2005. Clinical Medicine 6, 2: 2005-2006. https://doi.org/10.1258/147775006776173309.

[74] Nancy A. Pachana, Jacki Liddle, Nancye M. Peel, Elizabeth Beattie, Christine Juang, and Bob G. Knight. 2014. Can We Do Better? Researchers' Experiences with Ethical Review Boards on Projects with Later Life as a Focus. Journal of Alzheimer's Disease 43, 3: 701-707. https://doi.org/10.3233/JAD-141956.

[75] Institute of Medicine (US) Committee on Assessing the System for Protecting Human Research Participants, Daniel D. Federman, Kathi E. Hanna, and Laura Lyman Rodriguez. 2002. Back to Basics: Scientific, Conflict of Interest, and Ethical Review of Research Protocols. National Academies Press (US). Retrieved September 19, 2019 from https://www.ncbi.nlm.nih.gov/books/NBK43564/.

[76] Wanda Pillow. 2003. Confession, catharsis, or cure? Rethinking the uses of reflexivity as methodological power in qualitative research. International Journal of Qualitative Studies in Education 16, 2: 175-196. https://doi.org/10.1080/0951839032000060635.

[77] Thomas Scanlon. 1998. What We Owe to Each Other. Belknap Press of Harvard University Press.

[78] silicon. 2017. The battle for ethics at the cutting edge of technology. Silicon Republic. Retrieved September 20, 2019 from

https://www.siliconrepublic.com/machines/ethics-tec hnology-fiachra-o-brolchain-dcu.

[79] Laura Stark. 2007. Victims in Our Own Minds? IRBs in Myth and Practice. Law \& Society Review 41, 4: 777-786. https://doi.org/10.1111/j.1540-5893.2007.00323.x.

[80] Sanna Talja, Kimmo Tuominen, and Reijo Savolainen. 2005. "Isms" in information science: constructivism, collectivism and constructionism. Journal of Documentation 61: 79-101. https://doi.org/10.1108/00220410510578023.

[81] Maria Dolores C. Tongco. 2007. Purposive Sampling as a Tool for Informant Selection. https://doi.org/10.17348/era.5.0.147-158.

[82] Austin L. Toombs, Andy Dow, John Vines, Colin M. Gray, Barbara Dennis, Rachel Clarke, and Ann Light. 2018. Designing for Everyday Care in Communities. In Proceedings of the 2018 ACM Conference Companion Publication on Designing Interactive Systems (DIS '18 Companion), 391-394. https://doi.org/10.1145/3197391.3197394. 
[83] Cathy Treadaway and Gail Kenning. 2016. Sensor e-textiles: person centered co-design for people with late stage dementia. Working with Older People. https://doi.org/10.1108/WWOP-09-2015-0022.

[84] Julia Twigg and Christina E. Buse. 2013. Dress, dementia and the embodiment of identity: Dementia. https://doi.org/10.1177/1471301213476504.

[85] David Unbehaun, Konstantin Aal, Daryoush Daniel Vaziri, Rainer Wieching, Peter Tolmie, and Volker Wulf. 2018. Facilitating Collaboration and Social Experiences with Videogames in Dementia: Results and Implications from a Participatory Design Study. Proceedings of the ACM on Human-Computer Interaction 2, CSCW: 175. https://doi.org/10.1145/3274444.

[86] David Unbehaun, Daryoush Daniel Vaziri, Konstantin Aal, Rainer Wieching, Peter Tolmie, and Volker Wulf. 2018. Exploring the Potential of Exergames to affect the Social and Daily Life of People with Dementia and their Caregivers. 62. https://doi.org/10.1145/3173574.3173636.

[87] John Vines, Roisin McNaney, Rachel Clarke, Stephen Lindsay, John McCarthy, Steve Howard, Mario Romero, and Jayne Wallace. 2013. Designing For- and With- Vulnerable People. In CHI '13 Extended Abstracts on Human Factors in Computing Systems (CHI EA '13), 3231-3234. https://doi.org/10.1145/2468356.2479654.

[88] John Vines, Róisín McNaney, Amey Holden, Ivan Poliakov, Peter Wright, and Patrick Olivier. 2017. Our Year With the Glass: Expectations, Letdowns and Ethical Dilemmas of Technology Trials With Vulnerable People. Interacting with Computers 29, 1: 27-44. https://doi.org/10.1093/iwc/iww017.

[89] Loïc Wacquant. 2015. For a Sociology of Flesh and Blood. Qualitative Sociology 38, 1: 1-11. https://doi.org/10.1007/s11133-014-9291-y.

[90] Jayne Wallace. 2013. Interaction Design, Heritage, and the Self. interactions 20, 5: 16-20. https://doi.org/10.1145/2500247.

[91] Jayne Wallace, John McCarthy, Peter C. Wright, and Patrick Olivier. 2013. Making design probes work. In Proceedings of the SIGCHI Conference on Human Factors in Computing Systems - CHI '13, 3441. https://doi.org/10.1145/2470654.2466473.

[92] Jayne Wallace, Anja Thieme, Gavin Wood, Guy Schofield, and Patrick Olivier. 2012. Enabling self, intimacy and a sense of home in dementia. In Proceedings of the 2012 ACM annual conference on Human Factors in Computing Systems - CHI '12, 2629. https://doi.org/10.1145/2207676.2208654.

[93] Jayne Wallace, Anja Thieme, Gavin Wood, Guy Schofield, and Patrick Olivier. 2012. Enabling self, intimacy and a sense of home in dementia. In
Proceedings of the 2012 ACM annual conference on Human Factors in Computing Systems - CHI '12, 2629. https://doi.org/10.1145/2207676.2208654.

[94] Jayne Wallace, Peter C. Wright, John McCarthy, David Philip Green, James Thomas, and Patrick Olivier. 2013. A Design-led Inquiry into Personhood in Dementia. In Proceedings of the SIGCHI Conference on Human Factors in Computing Systems (CHI '13), 2617-2626. https://doi.org/10.1145/2470654.2481363.

[95] Lin Wan, Claudia Müller, Dave Randall, and Volker Wulf. 2016. Design of A GPS Monitoring System for Dementia Care and Its Challenges in Academia-Industry Project. ACM Trans. Comput.-Hum. Interact. 23, 5: 31:1-31:36. https://doi.org/10.1145/2963095.

[96] Lin Wan, Claudia Müller, Volker Wulf, and David William Randall. 2014. Addressing the Subtleties in Dementia Care: Pre-study \& Evaluation of a GPS Monitoring System. In Proceedings of the SIGCHI Conference on Human Factors in Computing Systems (CHI '14), 3987-3996. https://doi.org/10.1145/2556288.2557307.

[97] Jenny Waycott, Hilary Davis, Anja Thieme, Stacy Branham, John Vines, and Cosmin Munteanu. 2015. Ethical Encounters in HCI: Research in Sensitive Settings. In Proceedings of the 33rd Annual ACM Conference Extended Abstracts on Human Factors in Computing Systems (CHI EA '15), 2369-2372. https://doi.org/10.1145/2702613.2702655.

[98] Jenny Waycott, Greg Wadley, Stefan Schutt, Arthur Stabolidis, and Reeva Lederman. 2015. The Challenge of Technology Research in Sensitive Settings. In Proceedings of the Annual Meeting of the Australian Special Interest Group for Computer Human Interaction on - OzCHI '15, 240-249. https://doi.org/10.1145/2838739.2838773.

[99] Daniel Welsh, Kellie Morrissey, Sarah Foley, Roisin McNaney, Christos Salis, John McCarthy, and John Vines. 2018. Ticket to Talk: Supporting Conversation Between Young People and People with Dementia Through Digital Media. In Proceedings of the 2018 CHI Conference on Human Factors in Computing Systems (CHI '18), 375:1-375:14. https://doi.org/10.1145/3173574.3173949.

[100] Sarah Myers West. 2019. Data Capitalism: Redefining the Logics of Surveillance and Privacy. Business and Society 58, 1: 20-41. https://doi.org/10.1177/0007650317718185.

[101] Symptoms. Alzheimer's Society. Retrieved September 19, 2019 from https://www.alzheimers.org.uk/about-dementia/sympt oms-and-diagnosis/symptoms. 
[102] WMA - The World Medical Association-WMA Declaration of Helsinki - Ethical Principles for Medical Research Involving Human Subjects. Retrieved September 17, 2019 from https://www.wma.net/policies-post/wma-declarationof-helsinki-ethical-principles-for-medical-research-in volving-human-subjects/.
[103] Dementia Lab 2020 / Supporting Ability / The Conference. Retrieved December 24, 2019 from http://www.dementialabconference.com 